\title{
Panorama da compra de alimentos da agricultura familiar para o Programa Nacional de Alimentação Escolar
}

\author{
Panorama of purchasing food products from family farmers \\ for the Brazilian School Nutrition Program
}

Elisa Braga Saraiva ${ }^{1}$

Ana Paula Ferreira da Silva ${ }^{2}$

Anete Araújo de Sousa ${ }^{1}$

Gabrielle Fernandes Cerqueira ${ }^{3}$

Carolina Martins dos Santos Chagas ${ }^{3}$

Natacha Toral ${ }^{3}$

${ }^{1}$ Centro Colaborador em Alimentação e Nutrição do Escolar de Santa Catarina, Universidade Federal de Santa Catarina. Campus Universitário, Centro de Ciências da Saúde,

Departamento de Nutrição sala ${ }^{\circ} 205$, Trindade. 88040-970 Florianópolis Santa Catarina. ebsaraiva@gmail.com ${ }^{2}$ Programa de Pósgraduação em Nutrição, Universidade Federal de Santa Catarina.

${ }^{3}$ Centro Colaborador em Alimentação e Nutrição do Escolar, Universidade de Brasília.

\begin{abstract}
This article seeks to describe the viewpoint of purchasing food products from family farmers, analyzing their performance within the new guidelines of the Brazilian School Nutrition Program (PNAE). It is a critical assessment based on a review of the literature and the official data provided by the National Fund for the Development of Education/Ministry of Education relating to 2010. The program budget in 2010 was approximately $R \$ 2.5$ billion and attended 45.6 million children, adolescents and adults. From the total amount, $R \$ 150,397,052.68$ was allocated for the purchase of agricultural products from family farmers. In Brazil, $47.4 \%$ of the local councils acquired food products from family farmers for the Brazilian School Nutrition Program and the purchase percentage was, on average, $22.7 \%$. Given the nature of recent legislation, other aspects should be explored in order to strengthen the compliance with the regulations in different Brazilian contexts and thus contribute both to local economic development and the provision of school meals which fulfill the principles of a healthy and adequate diet.
\end{abstract}

Key words School meals, School health care, Sustainable agriculture, Nutrition and food programs and policies
Resumo $O$ artigo tem por objetivo apresentar um panorama da compra de alimentos provenientes da agricultura familiar, analisando o seu cumprimento frente às novas diretrizes de execução do Programa Nacional de Alimentação Escolar (PNAE). Trata-se de ensaio crítico realizado com base em revisão da literatura e em dados oficiais fornecidos pelo Fundo Nacional de Desenvolvimento da Educação/Ministério da Educação/PNAE, referentes às prestações de contas dos órgãos gestores municipais relativas ao exercício 2010. O orçamento do PNAE em 2010 foi de aproximadamente $R \$ 2,5$ bilhões e beneficiou 45,6 milhões de estudantes da educação básica e de jovens e adultos. Deste montante, R\$150.397.052,68 foram destinados para a compra da agricultura familiar. No Brasil, 47,4\% dos municípios adquiriram alimentos da agricultura familiar para o PNAE e o percentual médio de compra nestes municípios foi de 22,7\%. Em função do caráter recente da legislação, destaca-se a necessidade de organização de gestores e agricultores para a efetivação desta normativa nos diferentes contextos brasileiros e assim contribuir tanto para o desenvolvimento econômico local, como para o fornecimento de refeições aos escolares que atendam aos princípios de uma alimentação saudável e adequada.

Palavras-chave Alimentação escolar, Saúde escolar, Agricultura sustentável, Programas e políticas de nutrição e alimentação 


\section{Introdução}

O Programa Nacional de Alimentação Escolar (PNAE) é a maior e mais antiga política pública no Brasil. A alimentação escolar é defendida como um direito dos estudantes e considerada uma das estratégias de Segurança Alimentar e Nutricional (SAN). Recentemente, novas diretrizes de execução do PNAE foram estabelecidas a partir da Lei Federal no 11.947 e da Resolução no 38/Fundo Nacional de Desenvolvimento da Educação (FNDE), promulgadas em julho de $2009^{1,2}$.

O FNDE faz os repasses de verbas provenientes do governo federal para a alimentação escolar dos estados e municípios, com base no número de alunos matriculados na educação básica. Uma das diretrizes estipula que, no mínimo, trinta por cento $(30 \%)$ do total destes recursos sejam destinados à compra de alimentos, preferencialmente orgânicos, produzidos pela agricultura familiar (AF), local, regional ou nacional ${ }^{1,2}$. O Programa, a partir destas diretrizes, tornou-se um importante segmento institucional para aquisição de alimentos da agricultura familiar.

Neste contexto, o estímulo e o apoio à agricultura familiar têm se mostrado relevantes para a formulação e a implementação de ações municipais de SAN e de desenvolvimento local, que visem promover o Direito Humano à Alimentação Adequada (DHAA) ${ }^{3-5}$. Assim, a produção de alimentos, especialmente a da agricultura familiar, tem se fortalecido com iniciativas de articulação de políticas públicas, a exemplo do PNAE com o Programa de Aquisição de Alimentos (PAA) e o Programa Nacional de Fortalecimento da Agricultura Familiar (PRONAF).

Dados do Conselho Nacional de Segurança Alimentar e Nutricional sobre a produção da AF mostram a contribuição que este segmento representa na produção de alimentos para o mercado interno, destacando a necessidade de apoiar este modelo produtivo, por meio de políticas agrárias e agrícolas, bem como a valorização da produção destes agricultores ${ }^{6}$.

Em função do caráter recente da legislação, análises da compra de alimentos para a alimentação escolar são relevantes, considerando a necessidade de fortalecer a agricultura familiar, de estimular a utilização de alimentos regionais, ou seja, que respeite os hábitos alimentares locais e o aumento do consumo de alimentos in natura por parte dos escolares, como definido nas diretrizes do $\mathrm{PNAE}^{2}$.

Diante destas considerações, o presente artigo tem como objetivo apresentar um panorama da compra de alimentos provenientes da AF, analisando o seu cumprimento frente às novas diretrizes de execução do PNAE.

Inicialmente, é apresentada a evolução histórica da aquisição dos alimentos para o PNAE, com base na legislação nacional da alimentação escolar. Em seguida, são pontuadas as informações sobre a AF no Brasil, a partir da literatura científica sobre o tema. Posteriormente, é analisado o percentual de compras de alimentos da AF, com base em dados oficiais fornecidos pelo FNDE/MEC referente ao exercício 2010, bem como as justificativas do não atendimento dos $30 \%$ por parte dos municípios. O artigo finaliza com a discussão dos desafios e perspectivas de ampliação da compra de alimentos da AF para a alimentação escolar.

\section{Evolução histórica da compra}

de alimentos para a alimentação escolar

A evolução da gestão da alimentação escolar no Brasil, no que diz respeito ao planejamento e à forma de aquisição de alimentos, tais como o processo de descentralização dos recursos, a obrigatoriedade para a compra de alimentos básicos e a determinação da lista de alimentos básicos na elaboração de cardápios, foi determinante para o fortalecimento do Programa e da AF.

De 1955 até 1993 a gestão da alimentação escolar era centralizada. Os cardápios eram planejados pelo órgão gerenciador (Ministério da Educação), os gêneros eram adquiridos via processo licitatório e a distribuição era realizada para todo o território nacional ${ }^{7}$.

A partir de 1994, a Lei n 8.913, de 12/07/1994 promove a descentralização dos recursos, ficando a execução do programa sob responsabilidade das Secretarias de Educação dos municípios, dos Estados e do Distrito Federal. O gerenciamento do programa passa a ser realizado pelo Fundo Nacional de Desenvolvimento da Educação (FNDE) por meio da Medida Provisória no 1784 , de 14/12/1998 ${ }^{7}$. Outra vantagem deste processo foi a redução ou a exclusão dos alimentos formulados, pré-processados, desidratados no cardápio que exigiam pouco tempo de pré-preparo, sem refrigeração, baixos volumes e menor peso, muitas vezes necessitando apenas do acréscimo de água ${ }^{8,9}$.

Ainda, a Medida Provisória ${ }^{\circ}$ 2178, de 28/ 06/2001 torna obrigatório o percentual de $70 \%$ dos recursos provenientes do FNDE para a aquisição de gêneros básicos, devendo-se respeitar os hábitos alimentares regionais, a vocação agríco- 
la do município e promovendo o desenvolvimento da economia local ${ }^{7}$.

A Resolução/CD/FNDE n ${ }^{\circ} 15$ de 16/06/2003 estabelece critérios e formas de transferência de recursos do PNAE, e determina a lista de alimentos básicos a serem utilizados na elaboração dos cardápios ${ }^{7}$.

Recentemente, diretrizes de execução do PNAE foram estabelecidas através da Lei $n^{\circ}$ 11.947/2009 e da Resolução no 38/FNDE/2009. O principal avanço refere-se ao percentual para a compra de alimentos: no mínimo, trinta por cento (30\%) do total de recursos repassados pelo FNDE devem ser destinados à compra de alimentos, preferencialmente orgânicos, produzidos pela agricultura familiar local, regional ou nacional, priorizando-se os assentamentos da reforma agrária, as comunidades tradicionais indígenas e as comunidades quilombolas ${ }^{1,2}$.

Esta mesma Resolução ${ }^{2}$ estabeleceu diretrizes para o Programa, quais sejam: o emprego da alimentação saudável e adequada; a inclusão da educação alimentar e nutricional no processo de ensino aprendizagem; a descentralização das ações e a articulação, em regime de colaboração, entre as esferas de governo e o apoio ao desenvolvimento sustentável, com incentivos para a aquisição de gêneros alimentícios diversificados, produzidos e comercializados em âmbito local e preferencialmente pela agricultura familiar e por empreendedores familiares, priorizando as comunidades tradicionais indígenas e as de remanescentes de quilombos.

Portanto, a partir desta regulamentação, abriu-se mais um espaço de produção e comercialização para a agricultura familiar, além de promover o consumo de alimentos in natura por parte dos escolares, podendo reduzir assim a oferta de alimentos processados ${ }^{1}$.

A aproximação entre agricultores familiares e consumidores tem promovido uma integração baseada em princípios de sustentabilidade, podendo contribuir com a redução do êxodo rural e da pobreza rural e urbana. A Lei $\mathrm{n}^{\circ} 11.947 /$ 2009, ao tornar obrigatória a compra da agricultura familiar, ampara o produtor quanto à aquisição dos alimentos e cria um meio para que este possa comercializar seus alimentos, através da dispensa do processo licitatório ${ }^{10}$.

\section{O PNAE como instrumento de fortalecimento da agricultura}

A Lei $\mathrm{n}^{\circ} 11.326$ de 2006 define como agricultor familiar e empreendedor familiar "os indiví- duos que praticam atividades no meio rural; não detenham mais que quatro módulos fiscais, ou seja, pequeno proprietário; utilizem mão de obra da própria família e tenha percentual mínimo da renda familiar originada de atividades econômicas do seu estabelecimento ou empreendimento, na forma definida pelo Poder Executivo" ${ }^{11}$.

A Companhia Nacional de Abastecimento (CONAB) destaca que a maior parte do abastecimento da mesa dos brasileiros é proveniente da agricultura familiar que responde por $7 \mathrm{de}$ cada 10 empregos no campo, ocupando $80 \%$ do setor rural. Em 2009, 60\% dos produtos que compuseram a cesta familiar distribuída pela CONAB foram da agricultura familiar ${ }^{12}$.

Portanto, o apoio a estes agricultores como forma de estimular a produção de alimentos sustentáveis é considerado essencial, não só por sua capacidade de geração de ocupação e de renda, como também pela maior diversidade e oferta de alimentos de qualidade, menor custo com transporte, confiabilidade do produto, preservação do hábito regional e da produção artesanal, promovendo uma conexão entre o campo e a cidade ${ }^{13,14}$.

$\mathrm{O}$ apoio à $\mathrm{AF}$ insere-se em um conjunto de ações públicas iniciadas na década de 1980. Estas ações, frutos de debates nacionais e internacionais, foram motivadas pela crise do desenvolvimento econômico no período, que gerou a instabilidade monetária, o endividamento, a desaceleração do crescimento econômico, o incremento da pobreza rural e urbana e a degradação dos recursos naturais ${ }^{15}$.

Na década de 1990, o Ministério da Agricultura e do Abastecimento criou o Programa de Valorização da Pequena Produção Rural (PROVAP), que serviu de base para a criação no Programa Nacional de Fortalecimento da Agricultura Familiar (PRONAF), em 19954.

Em 2003, foi criado o Programa de Aquisição de Alimentos (PAA) através da Lei ${ }^{\circ} 10.696$, dentro da estratégia federal que visa assegurar o DHAA e a SAN - o Programa Fome Zero ${ }^{16,17}$. O PAA tem por objetivo garantir o acesso aos alimentos em quantidade e regularidade aos indivíduos em insegurança alimentar e nutricional, a inclusão social no campo e a redução do êxodo rural. O Programa também contribui para a formação de estoques estratégicos, possibilitando aos agricultores familiares o armazenamento de seus produtos para posterior comercialização a um preço justo ${ }^{18}$.

Os responsáveis pela gestão deste programa são o Ministério do Desenvolvimento Agrário e 
o Ministério do Desenvolvimento Social e Combate à Fome juntamente com os governos estaduais, municipais, sociedade civil, organizações da $\mathrm{AF}$ e rede de entidades socioassistenciais ${ }^{18}$. O apoio à AF foi, portanto, inserido dentro das políticas públicas objetivando a SAN, por meio da distribuição de renda e geração de empregos.

Nas análises de Machado et al. ${ }^{19}$, a aquisição de alimentos do PAA para a alimentação escolar mostrou-se uma importante iniciativa para minimizar ou até mesmo sanar a deficiência no consumo de alimentos e ao mesmo tempo promover a produção familiar nos diferentes municípios. No conjunto destas políticas, o PAA foi uma das estratégias utilizadas por alguns municípios, antes do estabelecimento das novas diretrizes do PNAE em 20094.

Ainda, no processo de compras de produtos provenientes da agricultura familiar para o PNAE, os critérios utilizados são os mesmos do PAA: "dispensa do processo licitatório, desde que os preços sejam compatíveis com os praticados no mercado local e atendam aos critérios de qualidade" ${ }^{20}$.

No Quadro 1 são descritas as etapas de compra de alimentos da agricultura familiar para a alimentação escolar.

A observância do percentual de $30 \%$ da compra da AF é disciplinada pelo FNDE e poderá ser dispensada quando houver impossibilidade de emissão do documento fiscal correspondente; inviabilidade de fornecimento regular e constante dos gêneros alimentícios e condições higiênico-sanitárias inadequadas ${ }^{20}$.

Para isso, o FNDE utiliza instrumentos de prestação de compras. Um destes instrumentos é o Demonstrativo Sintético Anual (DSA) ${ }^{20}$ que apresenta um campo específico para que as Entidades Executoras informem quanto foi gasto do recurso do PNAE na compra de alimentos desse tipo de produtor rural. Outro instrumento é o Parecer Conclusivo dos Conselheiros de Alimentação Escolar $(\mathrm{CAE})^{20}$. Com base nestas informações é possível analisar e acompanhar a execução destas compras.

\section{Panorama das compras de alimentos da agricultura familiar no Brasil: exercício de 2010}

O orçamento do programa em 2010 foi de aproximadamente $\mathrm{R} \$ 2,5$ bilhões e beneficiou 45,6 milhões de estudantes da educação básica e de jovens e adultos ${ }^{7}$. Deste montante, R\$ 150.397.052,68 foram destinados para a compra da agricultura familiar, segundo dados do DSA, instrumento de prestação de contas dos municípios e estados, do PNAE/FNDE, 2010, em estudo realizado pela equipe do Centro Colaborador em Alimentação e Nutrição do Escolar da Universidade Federal de Brasília (Cecane/UnB).

A Tabela 1 apresenta o número de DSA analisados, por região do Brasil e a situação dos municípios e estados referente à compra da agricultura familiar para a alimentação escolar, segundo regiões e Brasil, no ano de 2010.

No Brasil, 47,4\% dos municípios adquiriram alimentos da AF para o PNAE e o percentual de compra nestes municípios foi, em média, de $22,7 \%$. A região Sul do país apresentou o maior percentual de compra de alimentos da agricultura familiar $(71,3 \%)$ e o Centro-Oeste apresentou o menor (35,3\%). Destaca-se que o ano de 2010 foi o primeiro ano de obrigatoriedade da compra da agricultura familiar e que um número considerável de municípios brasileiros já iniciou este processo.

Segundo dados do Censo Agropecuário 2006 a agricultura familiar no Brasil é responsável por parte da produção nacional, sendo $87 \%$ da produção de mandioca, $70 \%$ de feijão, $46 \%$ de milho, $38 \%$ de café, $34 \%$ de arroz, $58 \%$ do leite, $59 \%$ dos suínos, $50 \%$ das aves, $30 \%$ dos bovinos e $21 \%$ do trigo ${ }^{21}$.

Guilhoto et al. ${ }^{22}$ em estudo sobre a importância da agricultura familiar no Brasil indica que nas regiões Norte, Sul e Nordeste a AF tem uma contribuição expressiva para o Produto Interno Bruto (PIB). A região Centro-Oeste apresenta características de grandes propriedades e ênfase na exportação e a região Sul destaca-se na produção da AF e no abastecimento interno de alimentos, o que pode justificar os dados de compra da AF para a alimentação escolar nestas regiões.

Infere-se pelos resultados encontrados que há a necessidade do fortalecimento e da implementação de estratégias de diferentes setores públicos e da sociedade civil organizada para se colocar em prática o item da Resolução no 38/ FNDE/2009 sobre a compra de alimentos provenientes da agricultura familiar.

A Tabela 2 apresenta as justificativas para o não atendimento dos $30 \%$, conforme análise dos pareceres conclusivos emitidos pelos Conselheiros da Alimentação Escolar (CAE) ao FNDE.

Considerando os pareceres conclusivos, a maior causa para o não atendimento dos 30\% de compra da AF referiu-se a "Inviabilidade de fornecimento regular e constante" com $21,10 \%$ e "Outros" com 32,90\% dos relatos (alternativa 
Quadro 1. Adaptado do passo a passo da compra da agricultura familiar para o PNAE $^{2,20}$.

$1^{\circ}$ Passo: Planejamento dos gastos

Estabelecer o quanto será gasto com compras da agricultura familiar (mínimo 30\% do recurso do FNDE)

2o Passo: Cardápio - Responsável: Nutricionista RT

Mapear os produtos da agricultura familiar local

Elaborar cardápio respeitando a cultura alimentar local, a diversidade e a sazonalidade da produção da agricultura familiar da região

Informar à Entidade Executora (EE) a demanda (especificar produtos e quantidades)

3o Passo: Pesquisa de preço - Responsável: Entidade executora (EE)

A EE deverá considerar os preços de referência praticados pelo Programa de Aquisição de Alimentos - PAA (CONAB);

Nas localidades em que não houver PAA, os preços de referência deverão ser calculados com base em critérios definidos a partir do valor gasto no ano para compra da agricultura familiar.

40 Passo: Chamada pública - Responsável: Entidade Executora

Chamada Pública é um tipo de Edital para efetivar a aquisição de produtos da AF, com dispensa de licitação. A chamada pública deve fornecer informações necessárias para que os fornecedores apresentem corretamente os projetos de venda.

Divulgar a chamada pública em locais de ampla circulação.

5* Passo: Elaboração do projeto de venda - Responsável: Grupo formal e Entidade Articuladora* (Grupo informal)

É o documento que formaliza o interesse dos agricultores familiares em fornecer para a Alimentação Escolar. Deve estar em conformidade com a chamada pública.

60 Passo: Recebimento do projeto de venda - Responsável: EE e Agricultores Familiares

Documentação exigida para habilitação dos fornecedores:

- Grupo Formal: DAPa jurídica, CNPJ $^{\mathrm{b}}$, cópias das certidões negativas junto ao INSS ${ }^{\mathrm{c}}$, FGTS ${ }^{\mathrm{d}}$, Receita

Federal e Dívidas Ativas da União, cópia do estatuto e projeto de venda;

- Grupo Informal: DAP de cada agricultor familiar, $\mathrm{CPF}^{\mathrm{e}}$ e Projeto de venda.

7o Passo: Amostra para controle de qualidade - Responsável: Entidade Executora

Para a avaliação e seleção dos alimentos os produtores deverão encaminhar amostras para serem submetidas aos testes necessários após a fase de habilitação.

80 Passo: Seleção dos projetos de venda - Responsável: Entidade Executora

Terão prioridade nesta ordem os projetos do município, da região, do território rural, do estado e do país; assentamentos da reforma agrária, as comunidades tradicionais indígenas e as comunidades quilombolas; Grupos Formais sobre os Grupos Informais e os alimentos orgânicos;

Os produtos da agricultura familiar devem atender a legislação sanitária;

Limite individual de venda do agricultor familiar é de R\$20.000,00 por DAP/ano.

9o Passo: Assinatura do Contrato - Responsável: EE e Agricultores familiares fornecedores

O Contrato estabelece o cronograma de entrega dos produtos, data de pagamento dos agricultores familiares e cláusulas de compra e venda.

10 Passo: Entrega dos produtos - Responsável: Agricultores familiares fornecedores

O Termo de Recebimento atesta que os produtos entregues estão de acordo com o Contrato e com os padrões de qualidade; Documento fiscal.

* Entidade Articuladora: Entidades cadastradas no Sistema Brasileiro Descentralizado de Assistência Técnica e Extensão Rural (Sibrater), Sindicato dos Trabalhadores Rurais (STR), Sindicato dos Trabalhadores da Agricultura Familiar (Sintraf) e Entidades credenciadas pelo Ministério do Desenvolvimento Agrário para emissão de DAP. ( ${ }^{a}$ : DAP - Declaração de Aptidão ao Pronaf; ${ }^{\text {b: }}$

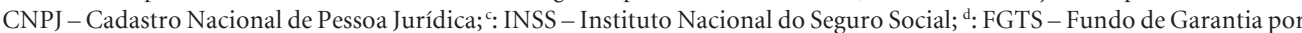
Tempo de Serviço; e:CPF - Cadastro de Pessoa Física.) 
Tabela 1. Resultado do percentual de recurso executado nos municípios e estados referente à aquisição de gêneros da agricultura familiar com base no Demonstrativo Sintético Anual (DSA) por regiões e Brasil. FNDE, 2010.

\begin{tabular}{|c|c|c|c|c|c|c|c|c|c|c|c|c|}
\hline & \multicolumn{12}{|c|}{ Regiões brasileiras } \\
\hline & \multicolumn{2}{|c|}{ Centro Oeste } & \multicolumn{2}{|c|}{ Nordeste } & \multicolumn{2}{|c|}{ Norte } & \multicolumn{2}{|c|}{ Sudeste } & \multicolumn{2}{|c|}{ Sul } & \multicolumn{2}{|c|}{ Brasil } \\
\hline & $\mathbf{n}^{\star}$ & $\%$ & $\mathbf{n}^{\star}$ & $\%$ & $\mathbf{n}^{\star}$ & $\%$ & $\mathbf{n}^{\star}$ & $\%$ & $n^{*}$ & $\%$ & $\mathbf{n}^{\star}$ & $\%$ \\
\hline Não houve compra & 105 & 23,3 & 471 & 27,5 & 76 & 21,5 & 428 & 26,3 & 129 & 10,9 & 1209 & 22,7 \\
\hline Houve Compra & 159 & 35,3 & 665 & 38,9 & 167 & 47,3 & 690 & 42,4 & 843 & 71,3 & 2524 & 47,4 \\
\hline Não informou/ Não se aplica & 186 & 41,3 & 572 & 33,4 & 110 & 31,1 & 507 & 31,2 & 209 & 17,7 & 1584 & 29,7 \\
\hline Total & 450 & 100 & 1708 & 100 & 353 & 100 & 1625 & 100 & 1181 & 100 & 5317 & 100 \\
\hline
\end{tabular}

Fonte: Análise elaborada pela equipe do Centro Colaborador em Alimentação e Nutrição do Escolar da Universidade Federal de Brasília (Cecane/UnB), a partir dos dados fornecidos pelo Demonstrativo Sintético Anual (DAS), instrumento de prestação de contas dos municípios, do Programa Nacional de Alimentação Escolar (PNAE)/Fundo Nacional de Desenvolvimento da Educação (FNDE), 2010.

*n: número total de DSAs analisados dos municípios e estados de cada região.

Tabela 2. Justificativa para o não atendimento aos $30 \%$ de recurso executado na compra da agricultura familiar - Brasil e Regiões. FNDE, 2010.

\begin{tabular}{|c|c|c|c|c|c|c|c|c|c|c|c|c|}
\hline & \multicolumn{12}{|c|}{ Regiões brasileiras } \\
\hline & \multicolumn{2}{|c|}{ Centro Oeste } & \multicolumn{2}{|c|}{ Nordeste } & \multicolumn{2}{|c|}{ Norte } & \multicolumn{2}{|c|}{ Sudeste } & \multicolumn{2}{|c|}{ Sul } & \multicolumn{2}{|c|}{ Brasil } \\
\hline & $\mathbf{n}^{\star}$ & $\%$ & $\overline{n^{*}}$ & $\%$ & $\mathbf{n}^{\star}$ & $\%$ & $n^{\star}$ & $\%$ & $\mathbf{n}^{\star}$ & $\%$ & $\mathbf{n}^{*}$ & $\%$ \\
\hline $\begin{array}{l}\text { Impossibilidade de emissão } \\
\text { de nota fiscal }\end{array}$ & 9 & 3,90 & 34 & 4,49 & 9 & 3,91 & 22 & 4,13 & 7 & 1,47 & 81 & 3,64 \\
\hline $\begin{array}{l}\text { Inviabilidade de } \\
\text { fornecimento regular e } \\
\text { constante de gêneros }\end{array}$ & 46 & 19,91 & 194 & 25,63 & 59 & 25,65 & 103 & 19,32 & 68 & 14,26 & 4702 & 21,10 \\
\hline $\begin{array}{l}\text { Condições higiênico- } \\
\text { sanitárias inadequadas }\end{array}$ & 5 & 2,16 & 17 & 2,25 & 9 & 3,91 & 8 & 1,50 & 16 & 3,35 & 55 & 2,47 \\
\hline Outros & 96 & 41,56 & 222 & 29,33 & 76 & 33,04 & 238 & 44,65 & 101 & 21,20 & 733 & 32,90 \\
\hline Processo Singular & 3 & 1,30 & 11 & 1,45 & 6 & 2,61 & 14 & 2,63 & 4 & 0,84 & 38 & 1,71 \\
\hline Não Informou & 81 & 35,06 & 297 & 39,23 & 90 & 39,13 & 172 & 32,27 & 164 & 34,38 & 804 & 36,09 \\
\hline Não se aplica & 20 & 8,66 & 81 & 10,70 & 22 & 9,57 & 45 & 8,44 & 165 & 34,59 & 333 & 14,95 \\
\hline
\end{tabular}

Fonte: Análise elaborada pela equipe do Centro Colaborador em Alimentação e Nutrição do Escolar da Universidade Federal de Brasília (Cecane/UnB), a partir dos dados analisados dos pareceres conclusivos emitidos pelos Conselhos de Alimentação Escolar (CAE) dos municípios, como instrumento de prestação de contas do Programa Nacional de Alimentação Escolar (PNAE)/Fundo Nacional de Desenvolvimento da Educação (FNDE), 2010. $n^{*}$ : número total de Parecer Conclusivo do CAE analisados dos municípios e estados de cada região.

prevista na análise, quando as justificativas não constavam na legislação), tais como: falta de interesse dos agricultores, demora da Prefeitura em elaborar a chamada pública, os agricultores já haviam destinado todos os gêneros para o PAA, dentre outros limites. Para este último item (outros), as regiões Sudeste $(44,65 \%)$ e Centro-Oeste $(41,56 \%)$ tiveram maior frequência de relatos. Para o item sobre inviabilidade de fornecimento regular e constante de alimentos, as regiões Norte e Nordeste apresentaram os maiores percen- tuais, com 33,04\% e 29,33\% de ocorrências, respectivamente.

Diante dos dados apresentados e dos parâmetros legais que devem ser seguidos pelas Entidades Executoras (EE) em relação à compra da $\mathrm{AF}$, destaca-se que ainda há muito a ser feito para a consolidação do mercado institucional entre os pequenos produtores e o PNAE, desde o planejamento e a organização da produção de alimentos, a apropriação por parte das EE das realidades agrícolas locais e regionais a serem refletidas 
na demanda em tipos de alimentos e épocas de demanda, a priorização e a qualificação operativa das EE (recursos humanos e materiais, integração entre secretarias envolvidas) até a distribuição dos alimentos e refeições nas escolas.

\section{Desafios e perspectivas}

da compra de alimentos da AF para o PNAE

A compra da AF para o PNAE é uma regulamentação recente. A inviabilidade de fornecimento regular e constante como justificativa para o não atendimento dos 30\% exige articulação entre quem compra (demanda de alimentos para as escolas dos municípios) e quem vende (oferta de alimentos produzidos pelos agricultores familiares). Neste espaço de interlocução, destaca-se que o planejamento dos cardápios escolares, como primeiro passo para a compra da AF, deve basear-se em novos referenciais: o de promoção da saúde conjugada à sustentabilidade ambiental, cultural, econômica e social.

Assim, o planejamento requer a verificação das características dos diferentes produtos, pois alguns alimentos possuem ciclo produtivo mais longo, outros são mais sensíveis às alterações climáticas (sazonalidade), interferindo no abastecimento. Ao mesmo tempo, os agricultores precisam realizar um planejamento da produção dos alimentos, de acordo com a demanda para reduzir as oscilações e garantir uma oferta estável de produtos ${ }^{23}$.

Real e Schneider ${ }^{10}$ destacam que apesar da obrigatoriedade da compra da AF alguns municípios ainda encontram dificuldades na aquisição destes alimentos, pela presença de grandes empresas do setor envolvidas na compra pública de alimentos.

Turpin $^{4}$ abordou a alimentação escolar como fator de desenvolvimento local por meio do apoio aos agricultores familiares. Discutiu que diante da nova legislação, a alimentação escolar ganha reforços que estimulam os agricultores familiares e permitem que sejam alcançados os seus objetivos, com ganhos aos escolares, agricultores e comunidade local, possibilitando discussões do PNAE frente à produção e desenvolvimento rural e suas relações com o consumo e a saúde pública.

Nesse sentido, do desenvolvimento local, é de fundamental importância o reconhecimento do papel interdependente das várias secretarias do poder executivo (tanto municipal quanto estadual) relacionadas ao tema, como agricultura, educação, fazenda ou administração, entre outras. O desenvolvimento local será potencializa- do na medida em que o gestor público, ou EE, consiga implementar a compra da agricultura familiar como uma ação verdadeiramente transversal dentro de políticas setoriais, prevendo desafios pendentes como o tema da assessoria técnica para agricultores, infraestrutura de logística e armazenagem, diagnóstico e interação com a realidade agrícola local/regional e, fundamentalmente, a criação de espaços ou fóruns participativos de debate e planejamento, envolvendo agricultores, gestores e escolas.

Carvalho $^{24}$ ao analisar experiências exitosas em municípios brasileiros, antes das novas diretrizes de execução do PNAE, ressaltou que as licitações sustentáveis na alimentação escolar têm promovido o desenvolvimento regional, a inclusão social, a movimentação da economia local, o consumo de alimentos mais frescos por parte dos escolares, a redução nos gastos com transportes e a promoção de educação alimentar e nutricional para além do espaço escolar, ou seja, o principal entrave para a compra de AF é a falta de planejamento, ou planejamento inadequado, do gestor para a execução da compra. Deve-se conhecer a realidade local dos agricultores para que o gestor possa planejar sua compra respeitando sazonalidades, vocação produtiva etc.

Portanto, o desafio é que a compra da AF supere a diretriz que destaca o mínimo de 30\% de compra para, de fato, compras que se baseiem em parcerias reais para o desenvolvimento sustentável local e regional.

\section{Considerações Finais}

Os resultados apresentados neste artigo mostraram que cerca da metade dos municípios brasileiros $(47,4 \%)$ adquiriram alimentos da $\mathrm{AF}$ para a alimentação escolar e o percentual de compras nestes foi, em média de 22,7\%, em 2010. A inviabilidade de fornecimento regular e constante, além de outros limites apresentados pelas EE, se destacou como justificativa para o não atendimento dos 30\%. A região Sul apresentou maior percentual de compra da AF possivelmente relacionado ao nível de organização dos produtores rurais e dos gestores da região. A região Centro Oeste apresentou o menor percentual de compras (35,3\%), o que pode estar relacionado ao predomínio de produção ligada ao agronegócio e à pouca produção agrícola familiar nesta região se comparada à região Sul.

Cabe ressaltar que o ano de 2010 foi o primeiro de obrigatoriedade da compra da agricul- 
tura familiar para o PNAE. A cada ano, novos avanços vêm sendo construídos e os dados de 2011 e 2012 provavelmente apontarão um percentual maior de compras, no total de municípios e no volume total das compras.

Destaca-se que dado ao caráter recente da legislação, outros aspectos deverão ser explorados por estudos futuros, de forma a fortalecer a efetivação da normativa nos diferentes contextos brasileiros e assim contribuir tanto para o desenvolvimento econômico local, como para o fornecimento aos escolares de refeições que atendam aos princípios de uma alimentação saudável e adequada.

\section{Colaboradores}

EB Saraiva participou da concepção e desenho do artigo, análise de dados, redação e revisão do texto. APF Silva participou da concepção e desenho do artigo, revisão bibliográfica, redação e revisão do texto. AA Souza participou da concepção e desenho do artigo, redação e revisão do texto. GF Cerqueira e CMS Chagas e N Toral participaram da concepção do artigo, análise de dados e revisão do texto.

\section{Agradecimentos}

Ao Fundo Nacional de Desenvolvimento da Educação (FNDE), a partir de parceria estabelecida com o Centro Colaborador em Alimentação e Nutrição do Escolar do Estado de Santa Catarina (CECANE/SC).

\section{Referências}

1. Brasil. Lei no 11.947 de 16 de junho de 2009. Dispõe sobre o atendimento da alimentação escolar e do Programa Dinheiro Direto na Escola aos alunos da educação básica. Diário Oficial da União 2009; 17 jun.

2. Brasil. Resolução/CD/FNDE no 38 de 16 de julho de 2009. Dispõe sobre o atendimento da alimentação escolar aos alunos da educação básica no Programa Nacional de Alimentação Escolar (PNAE). Diário Oficial da União 2009; 17 jun.

3. Maluf RS. Ações públicas locais de abastecimento alimentar. [periódico na Internet]. 2011. [acessado 2011 jul 13]. Disponível em: http://www.polis.org.br/ obras/arquivo_172.pdf

4. Turpin ME. A alimentação escolar como fator de desenvolvimento local por meio do apoio aos agricultores familiares. Segurança Alimentar e Nutricional 2009; 16(Supl. 2):20-42.

5. Valente FLS, Beghin N. Realização do Direito Humano à Alimentação Adequada e a Experiência Brasileira: Subsídios para a Replicabilidade. [periódico na Internet]. 2006. [acessado 2011 jul 14]. Disponível em: http://www.dhnet.org.br/dados/relatorios/r dhescas_br/relatores_valente_dh_alimentacao.pdf

6. Brasil. Conselho Nacional de Segurança Alimentar e Nutricional (CONSEA). A Segurança Alimentar e Nutricional e o Direito Humano à Alimentação Adequada no Brasil: indicadores e monitoramento da Constituição de 1988 aos dias atuais. Brasília: CONSEA; 2010.

7. Brasil. Fundo Nacional de Desenvolvimento da Educação (FNDE). Alimentação Escolar, Histórico. [Internet]. 2009. [acessado 2011 abr 19]. Disponível em http://www.fnde.gov.br/index.php/ae-historico

8. Domene SMA. A escola como ambiente de promoção da saúde e educação nutricional. Psicologia 2008; 19(Supl. 4):505-517.

9. Spinelli MAS, Canesqui AM. O programa de alimentação escolar no estado de Mato Grosso: da centralização à descentralização (1979 - 1995). Rev Nutr 2002; 15(Supl. 1):105-117.

10. Real LCV, Schneider S. O uso de programas públicos de alimentação na reaproximação do pequeno produtor com o consumidor: o caso do programa de alimentação escolar. Estudo \& Debate 2011 18(Supl. 2):57-79. 
11. Brasil. Casa Civil. Lei no .11 .326 de 24 de julho de 2006. Estabelece as diretrizes para a formulação da Política Nacional da Agricultura Familiar e Empreendimentos Familiares Rurais. Diário Oficial da União 2006; 24 jul.

12. Companhia Nacional de Abastecimento. Agricultura familiar. [Internet]. 2011. [acessado 2011 jun 15]. Disponível em: http://www.conab.gov.br/ conteudos.php? $\mathrm{a}=1125 \& \mathrm{t}=1$

13. Brasil. Conselho Nacional de Segurança Alimentar e Nutricional. Princípios e diretrizes de uma politica de segurança alimentar e nutricional. Textos de referência da II Conferência de Segurança Alimentar e Nutricional. [Internet]. 2004. [acessado 2011 jun 29]. Disponível em: http://www4.planalto.gov.br/ consea/publicacoes/publiucacoes-arquivos/principios-e-diretrizes-de-uma-politica-de-san

14. Triches RM, Schneider S. Alimentação Escolar e Agricultura Familiar: reconectando o consumo à produção. Saúde e Sociedade 2010; 19(Supl. 4):933945.

15. Bonnal P, Maluf RS. Políticas de desenvolvimento territorial e multifuncionalidade da agricultura familiar no Brasil. Política \& Sociedade 2011; 8(Supl. 14):211-250.

16. Brasil. Lei $n^{\circ} .10 .696$ de 02 de julho de 2003. Dispõe sobre repactuação e o alongamento de dívidas oriundas de operações de crédito rural, e dá outras providências. Diário Oficial da União 2003; 02 jul.

17. Brasil. Conselho Nacional de Segurança Alimentar e Nutricional. [Internet]. 2011. [acessado 2011 jun 14]. Disponível em: http://www4.planalto.gov.br/ consea/consea-2

18. Brasil. Ministério do Desenvolvimento Agrário. Programa de Aquisição de Alimentos. [Internet]. 2011. [acessado 2011 jun 14]. Disponível em: http://www. mda.gov.br/portal/saf/programas/paa

19. Machado AT, Santilli J, Magalhães R. A agrobiodiversidade com enfoque agroecológico: implicações conceituais e jurídicas. Brasília: Embrapa Informação Tecnológica; 2008.
20. Brasil. Ministério do Desenvolvimento Agrário. Passo a Passo - Como funciona a compra e venda de produtos da agricultura familiar? [Internet]. 2011. [acessado 2011 abr 22]. Disponível em: http://portal. mda.gov.br/portal/saf/arquivos/view/alimenta-oescolar/PASSOAPASSO_ALIMENTACAOESCOLAR_ AGRICULTURAFAMILIAR.ppt

21. Instituto Brasileiro de Geografia e Estatística (IBGE). Censo Agropecuário 2006: agricultura familiar, primeiros resultados. Brasil, Grandes Regiões e Unidades da Federação. Rio de Janeiro: IBGE; 2006.

22. Guilhoto JM, Ichihara SM, Silveira FG, Gaiger F, Diniz BPC, Azzoni CR, Moreira GRC. A Importância da agricultura familiar no Brasil e em seus estados. Núcleo de Estudos Agrários e Desenvolvimento Rural (NEAD), Ministério do Desenvolvimento Agrário MDA), Fundação Instituto de Pesquisas Econômicas (FIPE). [periódico na Internet]. 2007. [acessado 2012 abr 24]. Disponível em: htpp:// www.usp.br/feaecon/media/livros/file_459.pdf

23. Brasil. Ministério da Agricultura, Pecuária e Abastecimento. Cadeia produtiva de produtos orgânicos. Ministério da Agricultura, Pecuária e Abastecimento; Secretaria de Política Agrícola; Instituto Interamericano de Cooperação para a Agricultura [Internet]. 2007a. [acessado 2011 abr 22]. Disponível em: http:/ /www.ibraf.org.br/x_files/Documentos/Cadeia Produtiva_de_Produtos_Org\%C3\%A2nicos_S\%C3\%A9rie_ 24. Agroneg\%C3\%B3cios_MAPA.pdf

Carvalho DG. Licitações sustentáveis, alimentação escolar e desenvolvimento Regional: uma discussão sobre o poder de compra governamental a favor da sustentabilidade. Planejamento e políticas públicas 2009; 32:115-148.

Artigo apresentado em 23/09/2012 Aprovado em 29/10/2012

Versão final apresentada em 30/11/2012 
